\title{
Article
}

\section{The Assessment of Autoignition of Modified Jet Fuels}

\author{
Jerzy Merkisz ${ }^{1}$, Ireneusz Pielecha ${ }^{1, *(1)}$ and Anna Lęgowik ${ }^{2}$ \\ 1 Faculty of Civil and Transport Engineering, Poznan University of Technology, Piotrowo 3, \\ 60-965 Poznan, Poland; jerzy.merkisz@put.poznan.pl \\ 2 Air Force Institute of Technology, Ksiecia Boleslawa 6, 01-494 Warsaw, Poland; anna.legowik@itwl.pl \\ * Correspondence: ireneusz.pielecha@put.poznan.pl; Tel.: +48-61-224-4502
}

check for updates

Citation: Merkisz, J.; Pielecha, I.; Łegowik, A. The Assessment of Autoignition of Modified Jet Fuels. Energies 2021, 14, 633. https:// doi.org/10.3390/en14030633

Academic Editor: Leonid Tartakovsky Received: 6 December 2020

Accepted: 22 January 2021

Published: 27 January 2021

Publisher's Note: MDPI stays neutral with regard to jurisdictional claims in published maps and institutional affiliations.

Copyright: (C) 2021 by the authors Licensee MDPI, Basel, Switzerland. This article is an open access article distributed under the terms and conditions of the Creative Commons Attribution (CC BY) license (https:// creativecommons.org/licenses/by/ $4.0 /)$.

\begin{abstract}
The condition of the natural environment, including breathable air, indicates that actions are to be taken related to the reduction of exhaust emissions from transport. One of the sectors of transport is aviation. The reduction of emissions is tightly related to the types of fuels in this sector of transport. In the paper, the authors propose the application of a new generation of jet fuels. A full exploration of the physicochemical properties of these fuels requires research under actual engine operation. The conducted research pertains to the autoignition of modified jet fuels in terms of the thermodynamic indicators and optical analyses of the early phase of flame development. The investigations were conducted using a Rapid Compression Expansion Machine with a simultaneous recording of images using a high-speed camera. Owing to this technique, the authors could assess the thermodynamic properties and analyze the early flame development processes. The investigations enabled the assessment of fuel properties indicating an increased delay of the autoignition process compared to the reference fuel (diesel fuel). The performed analyses have confirmed a huge role of modern fuels (including HEFA in particular) in contemporary aviation-significant delay of autoignition at a simultaneous significant formation of autoignition spots and high intensification of combustion.
\end{abstract}

Keywords: jet fuels; fuel modification; autoignition; indicator research; optical research

\section{Introduction}

The problems related to the increasingly deteriorating condition of natural environment, including the atmosphere, have caused researchers to undertake works aiming at reducing the exhaust emissions from jet engines. This results from the fact that since the 1970s we have observed a dynamic advancement of air transport based on piston and jet engines mainly resulting from the increasing demand for the carriage of people and cargo. The impact of aircraft on the natural environment is heavily influenced by the design of engines (quality of combustion and fuel consumption).

One of the methods of reduction of exhaust emissions is the application of alternative fuels and biofuels in aviation engines. The most popular alternative fuels are ethanol and plant-based esters. Such fuels admitted for use in aviation must comply with precisely determined criteria such as: physicochemical properties that directly influence the combustion process, cost of production, availability, environmental impact, and safety-related requirements. Compared to conventional fuels, the share of biofuels in aviation is low but the interest in these fuels is increasing.

A rapid advancement of aviation transport expressed by a constant growth of the number of aircraft and air operations generates increasing exhaust emissions. An analysis of this problem was made in 1970 by carrying out research on the impact of the exhaust emissions from aircraft on the natural environment. The need to reduce these emissions was confirmed. The first to set forth and publish the exhaust emission standards was EPA (Environmental Protection Agency) in 1973. The standards referred to the emission of carbon monoxide, hydrocarbons, and nitrogen oxides. The standards related to the smoke opacity were published in 1976. In order to adapt the exhaust emission standards to the type 
and power output of the engine, seven different types of engines were distinguished [1-3]. The division was made in terms of the power output or thrust as well as type of design [3].

One of the methods of reduction of exhaust emissions is the application of alternative fuels and biofuels in jet engines.

We know and use a variety of biocomponents and biofuels in the road transport sector. However, due to the specific requirements in aviation, only some of them can be treated as potential biocomponents and biofuels for turbine jet engines. Biocomponents whose properties are close to regular jet fuel are FAME and biohydrocarbon fractions. Currently, the share of biocomponents and biofuels in aviation is small but the interest in these fuels is growing.

For many years, intense works have been underway to reduce the negative impact of transport on the natural environment. One of the strategic methods of minimizing the pollution is the introduction of increasingly stringent exhaust emission standards. Such actions force modern solutions such as modernization of engine design, development of alternative fuels, air traffic management, or exhaust emission control.

Owing to its intercontinental range and time efficiency and in light of the tight relation between the growing trend of the largest world economies and the expansion of the air carriage of goods and people, air transport has become a key element of the world transport system. Aviation transport generates $2 \%$ of the world greenhouse gases emission, approximately $6 \%$ of nitrogen oxides and below $1 \%$ of sulfur oxides [4], thus contributing to the negative impact on the environment and human health. The reason for this is the dynamic expansion of low-cost carriage to date influencing the number of air operations, thus a greater number of aircraft (only in 2015 planes carried over 560 million tourists and $35 \%$ of the total world cargo [5]).

The analyses of the search for new jet fuels pertain mainly to their mixtures with synthetic fuels: iso-paraffins [6] (a mixture of F-24 and Jet A), Fischer-Tropsch (F-T) [7-9] Alcohol-to-Jet [7,8,10], direct sugar to hydrocarbon (DSHC) [7], hydroprocessed esters and fatty acids (HEFA) [8] and bio-jet [7,11]. Simulation research is also being conducted related to alternative jet fuels $[6,12]$. The investigations of the jet fuels focus on the basic and operational research.

The first of the two pertains to the characteristics of combustion of the alternative fuels allowing for autoignition [9], flame propagation [13,14] and flame extinction [13].

Majority of the research pertains to the analyses of fast-varying processes in the rapid compression machine (RCM). Part of the works related to the properties of fuels is also conducted using a single pulse shock tube (SPST) and constant volume combustion chamber (CVCC).

The second of the two (development works) pertains to the problems of combustion quality of these fuels: soot formation [8], PM emission [15,16].

\section{Aim of the Research and Scientific Works}

The aim of the performed research was the determination of the impact of the modification of the JET type fuel on: (1) the capability of autoignition, and (2) the combustion process indexes related to the reference fuel. The research performed to date is mainly based on indicator analyses. In this paper, the authors focus on the analysis of the differences in the ignition of several fuels.

The following fuels were investigated: Jet A-1, biocomponent ATJ (Alcohol-to-Jet) and HEFA (Hydroprocessed Esters and Fatty Acids) in relation to the reference fuel (diesel fuel). The authors' choice was motivated by the interest in analyzing the pre-flame and early flame processes. The research was deemed justified, as the temperatures of the autoignition of these fuels are very similar.

A novelty in the performed research is the assessment of the initial stage of the fuel ignition. In order to obtain solutions to the problem, the authors investigated the ignition of the fuels, which corresponds to the glow ignition in jet engines. The use of positive ignition would significantly limit the amount of available information. 


\section{Characteristics of the Modification of Jet Fuels}

The Jet A-1 fuel for the turbine jet engines (kerosene) is manufactured from components obtained in a specified technological regime in the process of hydrodesulphurization, hydrocracking, and distillation. The components meet certain predefined quality requirements as per the ASTM D 1655 standard. The fuel contains additives (antioxidants and antielectrostatic agents). Table 1 presents the basic physicochemical parameters of the discussed fuels.

Table 1. Selected physicochemical properties of the fuels [17]

\begin{tabular}{|c|c|c|c|c|c|c|}
\hline No. & Property & Unit & Jet A-1 & ATJ & HEFA & Diesel \\
\hline 1. & Density at $15^{\circ} \mathrm{C}$ & $\mathrm{kg} / \mathrm{m}^{3}$ & 793.0 & 758.6 & 779.9 & 820 \\
\hline 2. & Viscosity at $-20^{\circ} \mathrm{C}$ & $\mathrm{mm}^{2} / \mathrm{s}$ & 3.062 & 4.740 & 5.004 & $\begin{array}{c}2.67 \\
\left.\text { (at } 40^{\circ} \mathrm{C}\right)\end{array}$ \\
\hline 3. & Calorific value & $\mathrm{MJ} / \mathrm{kg}$ & 43.231 & 44.027 & 43.70 & 43.4 \\
\hline 4. & Content of aromatics & $\%(\mathrm{~V} / \mathrm{V})$ & 17.3 & 0 & 9.4 & \\
\hline 5. & Flash point & ${ }^{\circ} \mathrm{C}$ & 38 & 47 & 67 & 52 \\
\hline 6. & Autoignition & ${ }^{\circ} \mathrm{C}$ & 210 & 210 & & 210 \\
\hline
\end{tabular}

The ATJ (Alcohol-to-Jet) fuel is obtained from sugar plants and cellulose biomass. In the process of fermentation, base alcohol is obtained that undergoes the process of distillation and hydrogenation. As a result, the produced fuel can form a mixture with kerosene used for turbine jet engines.

One of the processes of jet fuel production on an industrial scale is the HEFA (Hydroprocessed Esters and Fatty Acids) technology, in which the raw materials are plantbased oils, used oils, animal, and fish fat. The process of production of this biocomponent is divided into three stages:

- Hydroconversion of the triglycerides and fatty acids found in the plant-based oil,

- Selective cracking and isomerisation of paraffin hydrocarbons,

- Distillation of the wide isoparaffin fraction into individual products.

Diesel fuel is a mixture of paraffin, naphthene and aromatic hydrocarbons separated from crude oil in distillation processes. Due to a very high content of sulfur in the distillates, it is necessary to remove it through hydrogen processing in catalytic processes (hydrorefining).

Diesel fuels are also products obtained from the fractions remaining after distillation, only in this case, catalytic cracking or hydrocracking are necessary. The composition and the mutual proportions of hydrocarbons contained in the diesel fuel are different depending on the processed crude oil and the applied technologies.

\section{Indicator and Optical Research Methodology}

\subsection{Introduction}

For the cause and effect assessment of the engine operation (piston or flow machines) diagnostics of these engines is applied. Basic research mainly pertains to the processes of mixture formation and combustion while scientific and experimental works are mainly based on indicator and optical research [18]. The other research group involves analyses of the effects of the analyzed processes. These are typical diagnostic operations. Such diagnostics pertains to such diagnostic signals as the voltage-current signal [19], the vibroacoustic signal [20,21], the vibration-signal [22], and the emission-related signal [23].

When it comes to the exploration processes, despite widely popularized simulation methods $[24,25]$ experimental research and development works still remain significant. This is a solution including basic research using test engines (single or multi cylinder) and rapid compression machines [26-29]. These machines, owing to their research potential (including optical access), are widely used in the analysis of the process of injection and combustion [30] because they reduce the cost and improve the intensity of the development 
works compared to transparent engines. The investigations using the Rapid Compression Expansion Machine are performed with a view to adapting the obtained results to combustion engines. To this end, the said machine was used in the investigations of the pre-flame processes in relation to the ignitability of the discussed fuels.

The indicator tests were performed using a Rapid Compression Expansion Machine in order to determine: the indexes of the combustion process in the form of a cylinder pressure curves, the pressure change rates, the autoignition delay and to estimate the heat release rate. Typical solutions for these machines are a Rapid Compression Machine (RCM) [31,32] and a Rapid Compression Expansion Machine (RCEM) [33,34]. The first pertains to investigations, in which the pressure in the final stage of the compression obtains a constant value. The authors of this paper used the other option, in which the machine operating conditions correspond to the conditions of operation of an engine- the stroke of expansion is also allowed for.

The optical investigations were a supplement to the indicator ones. They were conducted simultaneously. This means that the indicator tracings corresponded to the combustion cycle and the recorded images inside the combustion chamber. Optical investigations allowed a relative determination of the autoignition spots inside the combustion chamber and the intensity of their formation. The process of combustion was carried out under lean mixture conditions (high excess air) in order to obtain a wide image spectrum of the autoignition spots. The investigations aimed at determining the indexes at small loads, at which the early flame formation processes are much longer and their course allows a detailed assessment.

\subsection{Measurement Equipment}

The investigations of the combustion process were carried out using:

1. A Rapid Compression Expansion Machine (RCEM) along with its accessories:

- An AK150 two-stage compressor (generating pressure for the piston rod)

- A system forcing the operation of the electromagnetic valves-a sequencer by HardSoft

- A combustion chamber heating system-pulse temperature regulator

2. The outstanding equipment consisted of:

- the fuel feed systems:

- an actuator system controlling the high pressure pump manufactured by Mechatronika

- a controller operating the high-pressure injector manufactured by Mechatronika

- the data acquisition system:

- a fast-varying data acquisition system AVL IndiSet 612

- a high-speed camera HSS5 by LaVision

- an MPC, camera and data acquisition synchronization system—a sequencer C711 by HardSoft.

The settings of the injection duration were realized using the sequencer (Figure 1) whose signal tracings (except the injection duration) also pertained to the movement of the piston of the Rapid Compression Expansion Machine and the initiation of the high-speed camera recording. The curve marked as 'outlet above the piston' indicates the opening of the exhaust valve (electromagnetic). Such operation makes the model of the machine closer to the operating conditions of a combustion engine. 


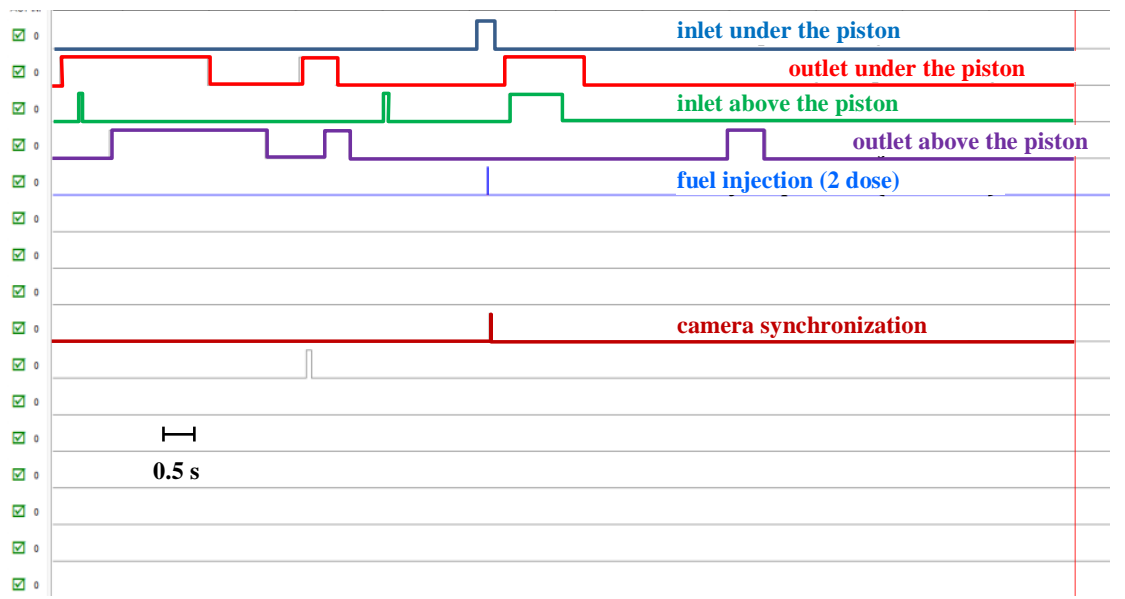

Figure 1. Settings of the TTL tracings with the description of their assignment.

The physical outputs in the form of BNC connectors (Figure 2-sequencer) were connected to both the fast-varying signal recording device (IndiModul 621) and the actuator controlling the electromagnetic valves of the machine.

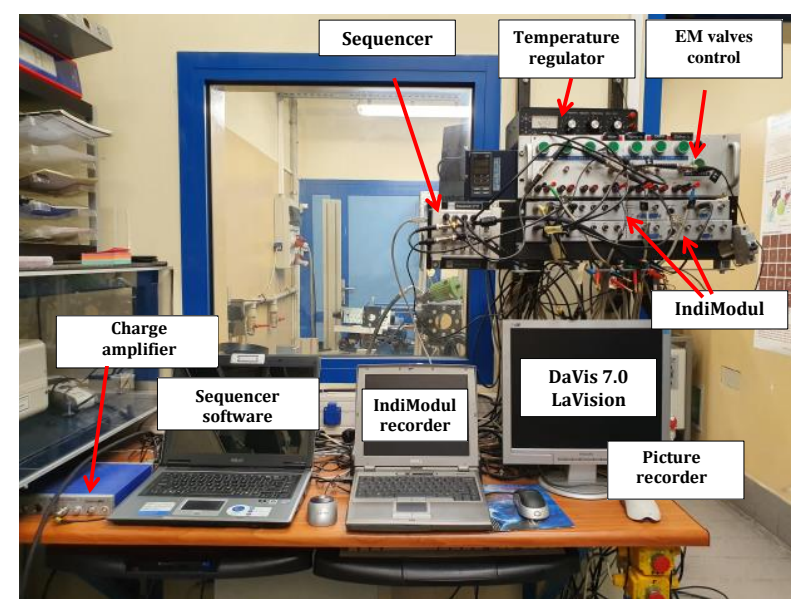

Figure 2. Controlling components of the RCEM, the data acquisition system (sequencer C711, AVL IndiModul 621), the image recording control device (HSS5 LaVision) and the connected measurement channels.

The tracings of the fast-varying quantities (presented in Figure 1) were stored with the use of AVL IndiModul 621 with the resolution of $1 \mathrm{kHz}$ (cylinder pressure-20 kHz) The method of connecting the measurement channels to the IndiModul 621 device has been shown in Figure 2.

The TTL controlling signals were connected to the $12 \mathrm{~V}$ or $24 \mathrm{~V}$ transformers (direct or alternating voltage, Figure 2 -valve controller). The device enabled controlling the electromagnetic valve manually or using the TTL signals. The manual control allowed resetting the RCEM to its initial settings in order to ensure the maximum piston displacement and scavenging the combustion chamber with fresh air.

The RCEM (Table 2, Figure 3) was fitted with the measurement-actuation equipment. The components of the equipment were coupled together through the HSD Sequencer C711 with a pre-programmed sequence of actions (activation of electromagnetic valves) in the controlling computer. The measurement signals from two AVL IndiModul 621 (6) modules were subject to acquisition (3) with the AVL IndiCom software. 
Table 2. Technical specifications of the RCEM.

\begin{tabular}{cc}
\hline Quantity & Value \\
\hline Cylinder displacement & $89 \mathrm{~mm}$ \\
Cylinder bore & $80 \mathrm{~mm}$ \\
Cylinder volume & $444 \mathrm{~cm}^{3}$ \\
Combustion chamber volume & $55 \mathrm{~cm}^{3}$ \\
Air feed & Eutlet \\
Piston drive & Electromagnetic valves \\
Compression ratio & Pneumatic \\
Type of combustion chamber & 14 \\
Piston deceleration method & Semi-spherical chamber inside the cylinder head+ in-cylinder chamber \\
Piston velocity & Pneumatic \\
Piston sealing & $1-3 \mathrm{~m} / \mathrm{s}$ depending on the air pressure under the piston \\
Optical access & Piston rings, PTFE sealing \\
Fuel injection & Quartz glass $\phi 48 \times 50$ mm located down of the piston combustion chamber \\
\end{tabular}

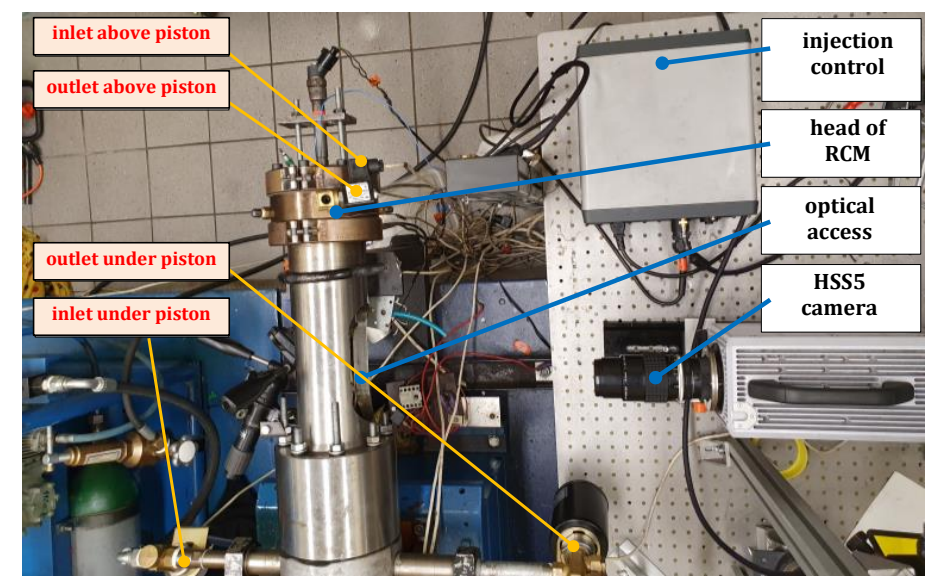

Figure 3. The RCEM and its components.

The sequence of the system operation and the range of analysis have been shown in Figure 4. Four tracings have been shown of the electromagnetic valves controlling the air above and under the piston along with the signals controlling the fuel injection and the camera synchronization.

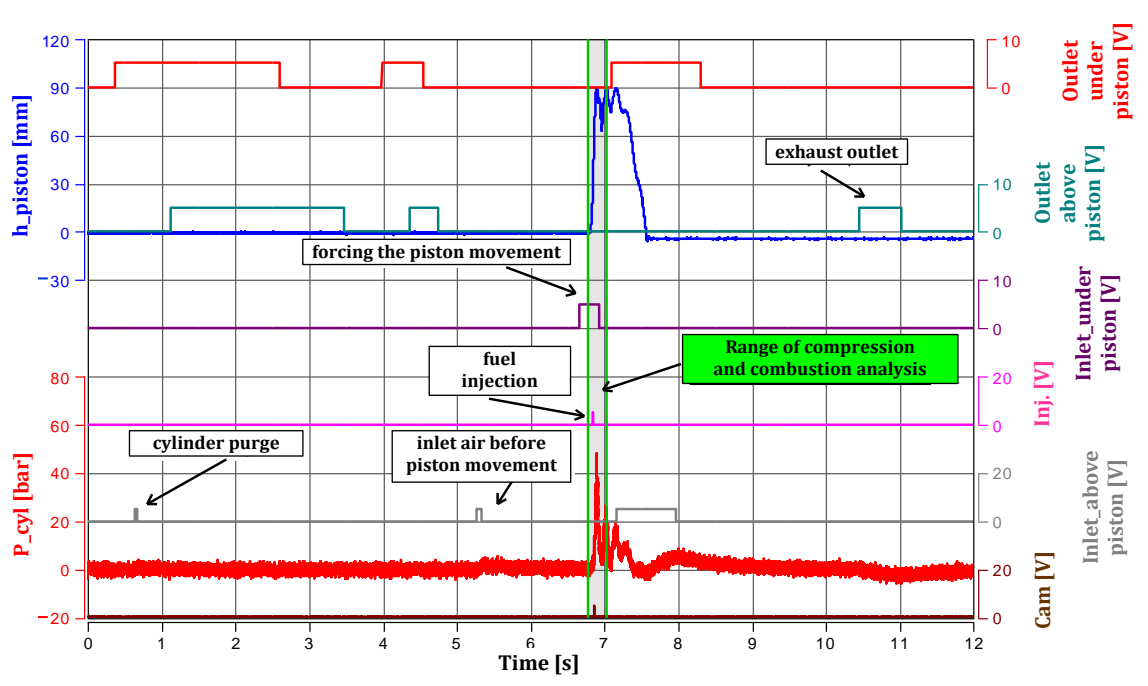

Figure 4. Range of operation of the system under analysis together with the entire sequence of operations of the electromagnetic valves. 
The investigated fuels were fed to the combustion chamber from the common rail system under the pressure of $50 \mathrm{MPa}$ (Figure 5). The system was fitted with a CP4 pump that, aside from injecting fuel, also allows the assessment of the unit fuel dose based on injection to the measurement glass. The realization of the multiple injections was carried out by the actuator presented in Figure 5 (fuel injection release).

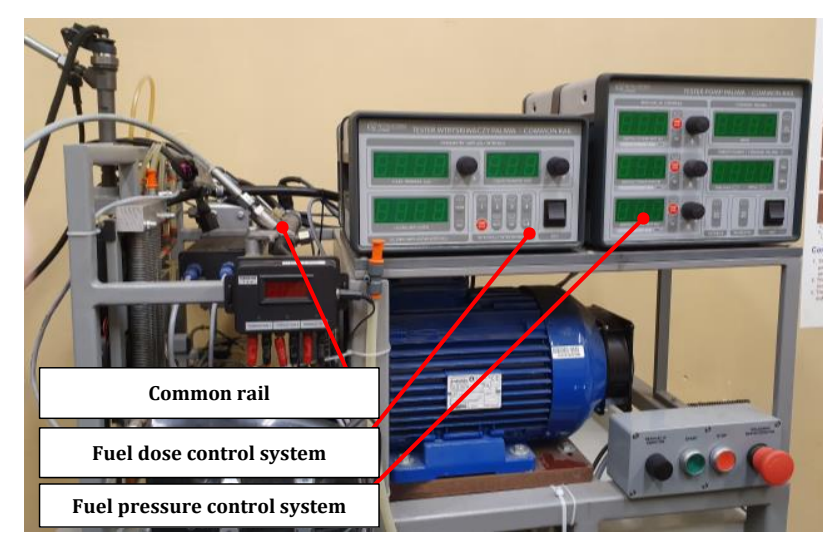

Figure 5. Common rail system by Mechatronika.

The optical investigations were carried out using a high-speed camera (HSS5 by LaVision, Figure 6). The camera was equipped with Nikon $50 \mathrm{~mm}$ lens and a 1:1.4 shutter. The camera matrix allows filming with the resolution of $1024 \times 1024$ at low frequency (up to $3 \mathrm{kHz}$ ). Increasing the filming frequency reduces the camera resolution. The camera was set at a distance of $32 \mathrm{~cm}$ from the angular mirror fitted in the sleeve and the piston rod of the RCEM. The distance of the mirror from the combustion chamber (with a quartz glass) was $106 \mathrm{~cm}$.

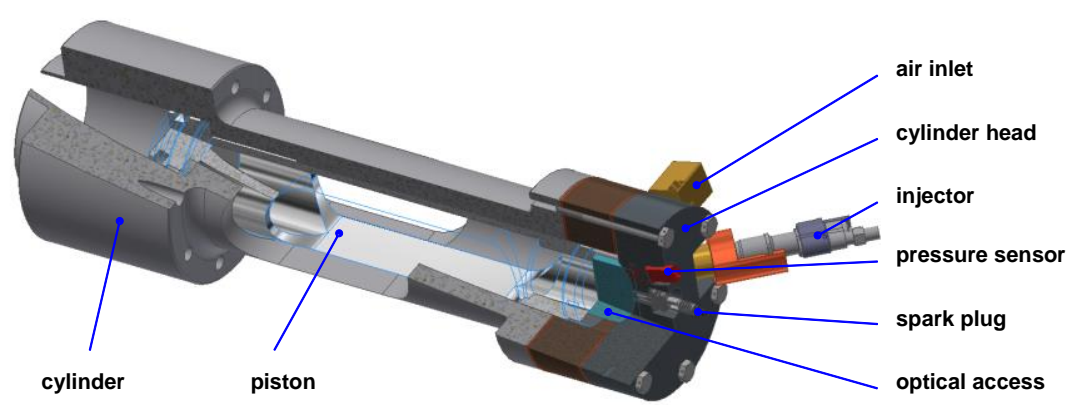

Figure 6. View of the optical stand for the analyses.

\subsection{Scope of the Research Works-Optical and Indicator Investigations}

Each fuel (diesel fuel, JET, HEFA30, ATJ30) was subjected to the same combustion trial under the following conditions-Table 3.

Table 3. Experimental conditions.

\begin{tabular}{ccc}
\hline Quantity & Value \\
\hline & Fuel & \\
Diesel & Base fuel \\
JET & $100 \%$ JET \\
ATJ30 & JET $+30 \%$ ATJ \\
HEFA30 & JET $+30 \% \mathrm{HEFA}$ \\
& Fuel injection & $50 \mathrm{MPa}$ \\
Injection pressure & & $50 \mathrm{deg} \mathrm{C}$ \\
Fuel dose & $0.7 \mathrm{~ms}(26.9 \mathrm{~mL})$ and $0.5 \mathrm{~ms}(16 \mathrm{~mL})$ dwell time: $11.8 \mathrm{~ms}$ \\
Fuel temperature & \\
\hline
\end{tabular}


Table 3. Cont.

\begin{tabular}{cc}
\hline Quantity & Value \\
\hline & Rapid Compression Expansion Machine \\
Compression pressure & $4 \mathrm{MPa}$ \\
Lambda value & $1.95-2.06$ \\
Air temperature & $293 \mathrm{~K}$ \\
Repetition & 3 \\
& \\
Image processor & Camera settings \\
Frequency & CMOS, $17 \mu \mathrm{m} \times 17 \mu \mathrm{m}, 10$-bit, monochromatic \\
Image & $5 \mathrm{kHz}$ \\
& $768 \times 768$ pixels \\
\hline
\end{tabular}

\section{Autoignition Investigations of the Modified Jet Fuels}

\subsection{Introduction and Aim of the Investigations}

The aim of the indicator and optical investigations was the determination of the influence of the JET fuel modification on the following:

(a) capability of autoignition

(b) indexes of the combustion process.

The indicator research was performed in order to determine: the combustion indexes in the form of a pressure curve inside the cylinder, the pressure change rate in time, the autoignition delay and to estimate the heat release rate.

The optical investigations were supplementary to the indicator ones and were carried out at the same time. This means that the indicator graph corresponds to the same combustion cycle. The optical research allowed a relative determination of the autoignition spots inside the combustion chamber and the rate of their formation. The combustion process was carried out under lean mixture conditions (high air excess ratio; $\lambda \sim 2.0$ ) in order to obtain a wide image spectrum related to the autoignition spots. The investigations did not aim at determining the indexes at high loads because, then, the early flame processes are much shorter and it is more difficult to assess them properly.

\subsection{Indicator Research of the Combustion Process (Autoignition Spots)}

The analysis of the autoignition process of fuels was conducted based on indicator and optical research. The indicator tracings were digitally filtered from the unprocessed signal of the in-cylinder pressure. The changes thereof and the unevenness of the combustion process have been presented in Figure 7.

From the analysis, it results that:

1. The highest combustion pressures were obtained for the ATJ30 fuel and the lowest for the diesel fuel.

2. The highest repeatability of the process was obtained for the HEFA 30 fuel and the lowest for the diesel fuel.

3. The smallest changes of the time of occurrence of the maximum pressure were observed for the HEFA30 fuel.

The repeatability of the cylinder pressure curve inside the cylinder during the entire process should correlate with the repeatability of the actuation of the piston movement in the RCEM.

From the analyzed figures, we know that the piston travel for the same point was $89 \mathrm{~mm}$. The differences result only from the different recording of the onset of the action of the piston rod in the RCEM. The course of the changes in the piston movement after TDC of the RCEM results from a different course of the combustion process. Despite the fact that the course of the averaged in-cylinder pressure presented in Figure 7 is similar, the local changes in the combustion process (not yet presented) are most likely incomparable due to the stochastic nature of the process-Figure 8 . 

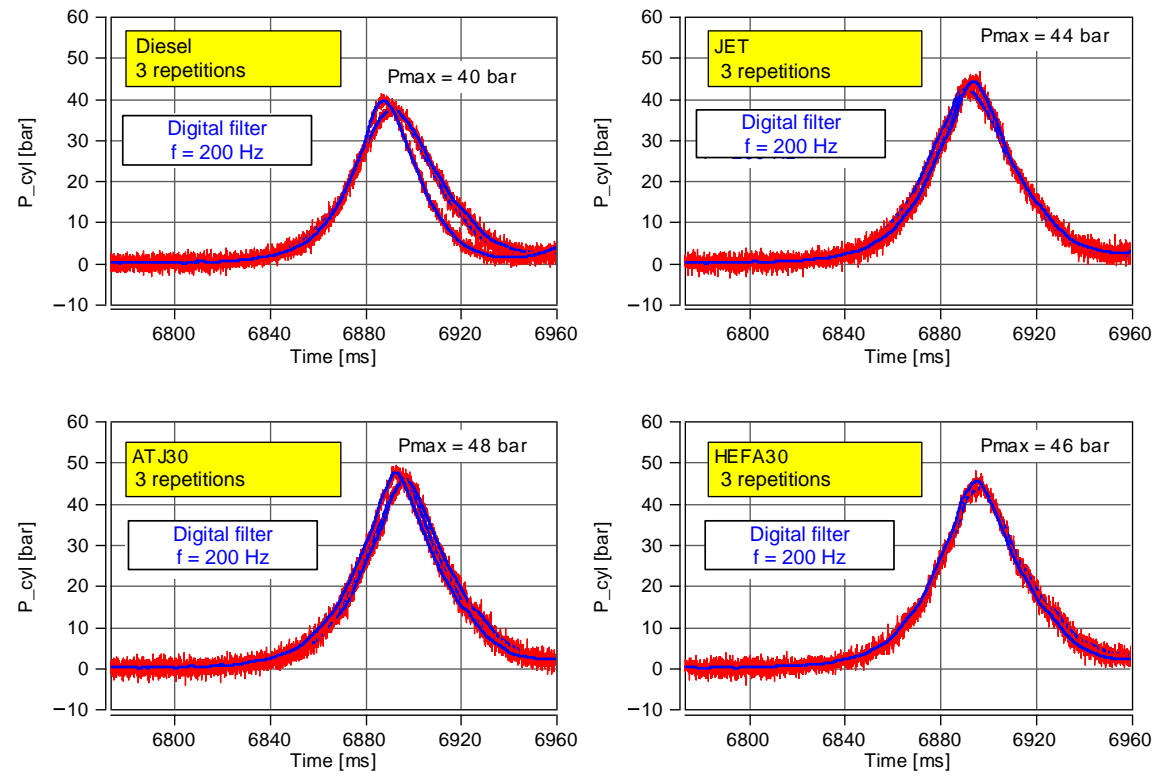

Figure 7. Assessment of the cylinder pressure curve inside the RCEM cylinder using three repetitions of combustion of a given fuel.
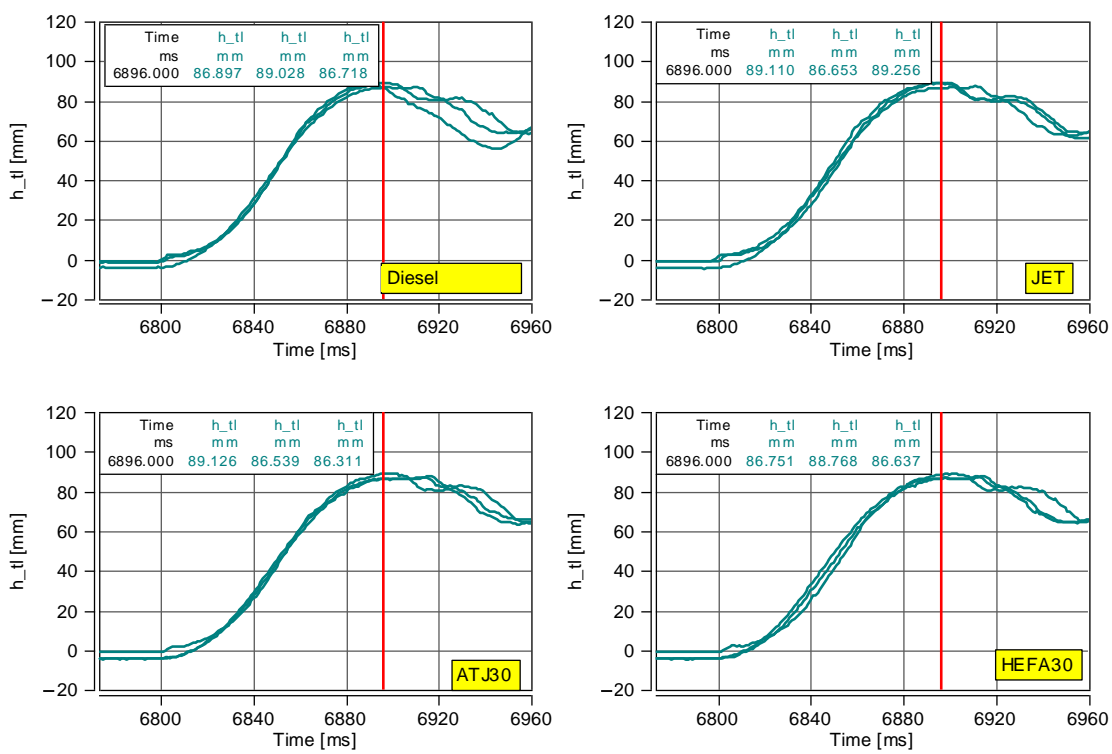

Figure 8. Piston travel curves for the analyzed processes.

\section{Assessment of Fuels in the Aspect of the Initial Combustion Process}

\subsection{Assessment of the Combustion Process Based on the Indicator Research}

The assessment of the combustion process started from the analysis of the curves of the in-cylinder pressure. Despite earlier similarities of the pressure curves, in this assessment, all the pressure curves of all the investigated fuels were overlain (Figure 9). From the analysis of the curves (different fuels), we know that they vary widely. Small deviations of the compression process result from the conditions of initiation of the piston movement (constant value of the piston actuation at 27 bar \pm 0.1 bar was maintained). 


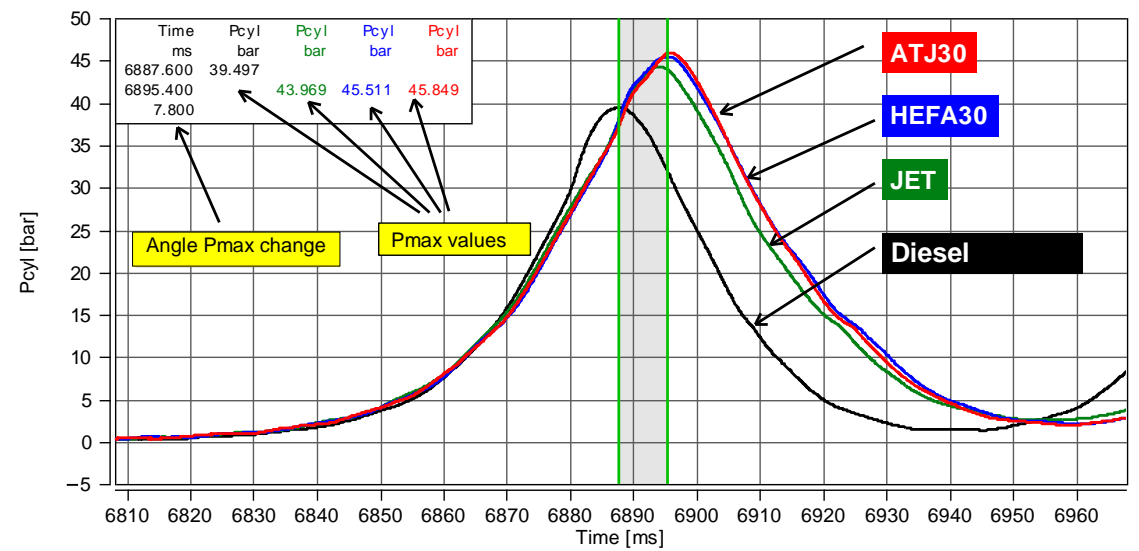

Figure 9. Assessment of the changes in the pressure curves in terms of comparison of the combustion processes.

Based on the performed observations, it was confirmed that:

1. Course of the combustion of diesel fuel varied from other fuels

2. Combustion of JET-based fuels resulted in a similar course of combustion; similar values of maximum pressure and slightly different angles of occurrence of the maximum pressure were obtained.

Further in the investigations, analyses of the indicator graph were conducted. To this end, the rate of pressure increment after autoignition was determined based on

$$
\frac{\mathrm{dPcyl}(\mathrm{t})}{\mathrm{dt}}=\frac{\mathrm{P}_{2}(\mathrm{t})-\mathrm{P}_{1}(\mathrm{t})}{\mathrm{t}_{2}-\mathrm{t}_{1}}
$$

where: $\mathrm{P}$-in-cylinder pressure; $\mathrm{t}-$ time of the process. Indexes denote the current and previous moment in time.

Using the Equation (1) the rates of pressure increment were determined for the analyzed fuels and the results have been presented in Figure 10.

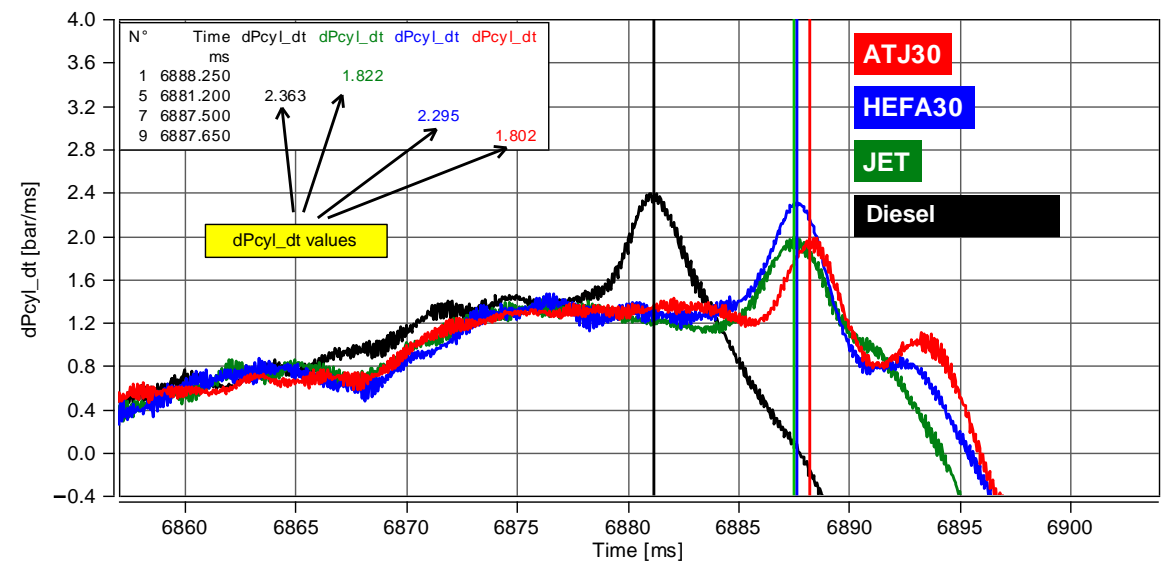

Figure 10. Change in the pressure increment rates after in-cylinder autoignition in terms of comparison of the combustion process.

The analysis of the in-cylinder pressure increment indicates the following:

1. Faster combustion process of the diesel fuel (Figure 9) is the effect of the earlier occurring pre-flame processes; the maximum value of $\mathrm{dPcyl} / \mathrm{dt}$ is close to the values of the outstanding fuels; 
2. Analysis of combustion of the outstanding fuels indicates a great deal of similarity in terms of the pre-flame processes: the highest value of dPcyl/dt was obtained for the combustion of the HEFA30 fuel.

Another combustion indicator was the analysis of the delay of the fuel autoignition (ID). The delay can be analyzed in the chemical $\left(\mathrm{t}_{\mathrm{CH}}\right)$ or physical $\left(\mathrm{t}_{\mathrm{PH}}\right)$ aspect

$$
\mathrm{t}_{\mathrm{ID}}=\mathrm{t}_{\mathrm{CH}}+\mathrm{t}_{\mathrm{PH}}
$$

When applying the RCEM, we do not have a typical crankshaft mechanism. Therefore the measurements were performed in the domain of time not the crankshaft angle. The results of the ignition delay are obtained directly (time $t_{\text {ID }}$ does not have to be calculated from the engine speed).

The most important factor in the chemical delay group influencing the changes in the autoignition delay is the fuel composition. Fuels containing large amounts of hydrocarbons in the olefin and paraffin series have a short period of autoignition delay (due to the easy decay of the hydrocarbon chains at elevated temperatures). A drop in the autoignition delay is observed for the increasing cetane number.

Out of the physical factors, the most important are: the density and viscosity of the fuel as well as its feed conditions: the temperature of the intake air (for lower intake air temperatures the autoignition delay is much greater-this explains the difficult engine start at low ambient temperatures), the pressure of the end of the compression stroke (for higher pressure values the autoignition delay decreases).

The autoignition delay $\left(\mathrm{t}_{\mathrm{ID}}\right)$ is the time or angle between the occurrence of the autoignition spots $\left(t_{\mathrm{SOC}}\right)$ and the onset of the fuel injection $\left(t_{\mathrm{FI}}\right)$. Because the investigations were carried out in relation to time, the form of the equation is

$$
\mathrm{t}_{\mathrm{ID}}=\mathrm{t}_{\mathrm{SOC}}-\mathrm{t}_{\mathrm{FI}}
$$

where: $\mathrm{t}_{\mathrm{SOC}}$-time of the start of combustion; $\mathrm{t}_{\mathrm{FI}}$-time of the onset of the fuel injection.

Start of combustion (with a certain level of simplification) can be assumed as the time of occurrence of the maximum pressure increment after the autoignition, which can be written as

$$
\mathrm{t}_{\mathrm{SOC}}=\left(\frac{\mathrm{dPcyl}}{\mathrm{dt}}\right)_{\max }
$$

The values of the above equation have already been shown in Figure 10. Supplementing the data with the values related to the onset of the fuel injection and carrying out calculations of Equation (4) we can obtain values of the autoignition delay of the investigated fuels. The physical form of this equation has been shown in Figure 11.

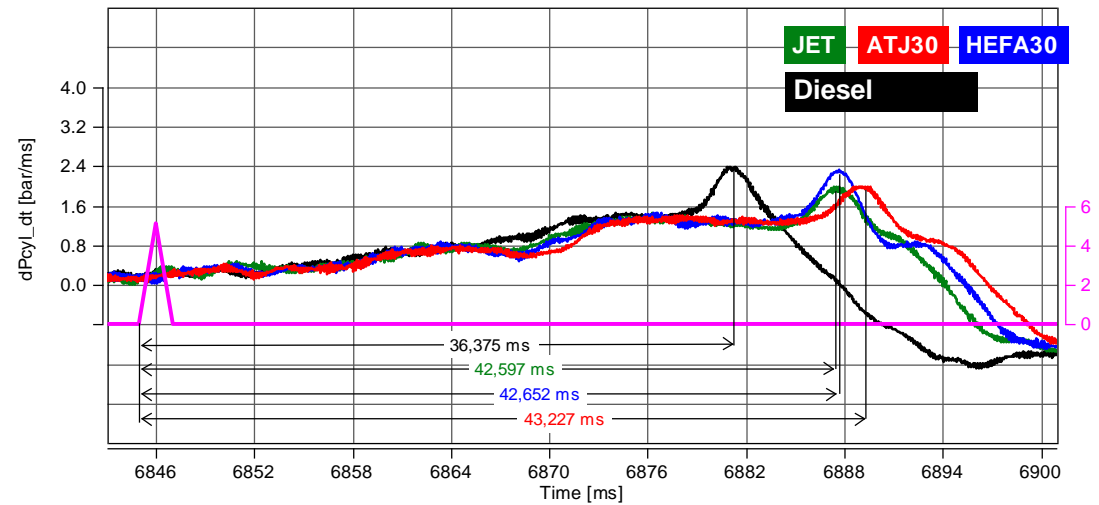

Figure 11. Obtained values of the autoignition delay of the investigated fuels. 
If we assume that the longest autoignition delay (ID) is $100 \%$ then we can determine the relative changes $t_{I D}$ for the analyzed fuels. For the investigations discussed in this paper they are:

- $\quad$ ATJ30-100\%,

- HEFA30-98.7\%,

- JET-98.5\%,

- $\mathrm{ON}-84.1 \%$.

From the above, we know that the ignition delay for the HEFA30 and the JET fuels is very similar. It is shorter by approximately $2 \%$ than that of the AJT30 fuel. The shortest autoignition delay was recorded for the diesel fuel.

Another stage in the thermodynamic calculations was the assessment of the heat release. The specificity of conducting research using RCEM requires a great amount of work in the form of actuation of the piston movement, which, at a low fuel dose and limited combustion (low increment of the combustion pressure) results in small amounts of released heat at a relatively high escape of heat to the cylinder walls. The cylinder walls and the walls of the combustion chamber were heated to the temperature of $90{ }^{\circ} \mathrm{C}$. Typical operating values in the combustion chamber are much higher. For this reason, significant negative values of the heat release were expected in the second stage of the process.

The analysis of the heat release was conducted based on the following equations:

Amount of heat

$$
\mathrm{dQ}=\mathrm{dW}+\mathrm{dU}
$$

After extension

$$
\mathrm{dQ}=\mathrm{pdV}+\mathrm{mCvdT}
$$

From the Clapeyron equation

$$
\mathrm{pV}=\mathrm{mRT}
$$

Calculating the derivative from both variables

$$
\mathrm{pdV}+\mathrm{Vdp}=\mathrm{mRdT}
$$

including

$$
\mathrm{mdT}=\frac{\mathrm{pdV}+\mathrm{Vdp}}{\mathrm{R}}
$$

Upon substituting to Equation (5) we obtain

$$
\mathrm{dQ}=\mathrm{pdV}+\mathrm{Cv}\left(\frac{\mathrm{pdV}+\mathrm{Vdp}}{\mathrm{R}}\right)
$$

From equation

$$
\mathrm{k}=\frac{\mathrm{Cp}}{\mathrm{Cv}} \text { and } \mathrm{Cp}-\mathrm{Cv}=\mathrm{R}
$$

It results that

$$
\begin{gathered}
\mathrm{Cp}=\mathrm{R}+\mathrm{Cv} \text { and } \mathrm{k}=\frac{\mathrm{R}+\mathrm{Cv}}{\mathrm{Cv}_{\mathrm{V}}}=\frac{\mathrm{R}}{\mathrm{Cv}}+1 \\
\frac{\mathrm{R}}{\mathrm{Cv}}=\mathrm{k}-1
\end{gathered}
$$

By substituting Equations (12) and (13) to Formula (10) we obtain

$$
\begin{gathered}
\mathrm{dQ}=\mathrm{pdV}+\frac{1}{\mathrm{k}-1}(\mathrm{pdV}+\mathrm{Vdp}) \\
\mathrm{dQ}=\mathrm{pdV}+\frac{1}{\mathrm{k}-1} \mathrm{pdV}+\frac{1}{\mathrm{k}-1} \mathrm{Vdp} \\
\mathrm{dQ}=\frac{\mathrm{k}-1+1}{\mathrm{k}-1} \mathrm{pdV}+\frac{1}{\mathrm{k}-1} \mathrm{Vdp}=\frac{\mathrm{k}}{\mathrm{k}-1} \mathrm{pdV}+\frac{1}{\mathrm{k}-1} \mathrm{Vdp}
\end{gathered}
$$


Eventually

$$
\mathrm{dQ}=\frac{\mathrm{k}}{\mathrm{k}-1} \mathrm{pdV}+\frac{1}{\mathrm{k}-1} \mathrm{Vdp}
$$

Allowing for the sealing of the cylinder of the RCEM and the piston travel velocity, the polytropic exponent $\mathrm{k}$ was assumed at 1.2.

The course of the combustion process generates certain consequences in the heat release process (release rate- $\mathrm{dQ}$ ), as is determined in a simplified relation (heat exchange with the walls was not taken into account, constant polytropic exponent)

$$
\frac{\mathrm{dQ}}{\mathrm{dt}}=\frac{\mathrm{k}}{\mathrm{k}-1}\left(\frac{\mathrm{P}_{\mathrm{n}+1}+\mathrm{P}_{\mathrm{n}}}{2}\right)\left(\mathrm{V}_{\mathrm{n}+1}-\mathrm{V}_{\mathrm{n}}\right)+\frac{1}{\mathrm{k}-1}\left(\frac{\mathrm{V}_{\mathrm{n}+1}+\mathrm{V}_{\mathrm{n}}}{2}\right)\left(\mathrm{P}_{\mathrm{n}+1}-\mathrm{P}_{\mathrm{n}}\right)
$$

in which an average value of the polytropic exponent was assumed at $k=1.32$ and indexes $\mathrm{n}$ and $\mathrm{n}+1$ denote the current and the next value of the in-cylinder pressure $(\mathrm{P})$ or the corresponding cylinder volume $(\mathrm{V})$.

Due to the low value of the fuel dose injected into the cylinder, the course of the changes in the heat release was close to the course of the pressure in the maximum range (Figure 12). Similarly to the course of the in-cylinder pressure, an early heat release was observed when combusting diesel fuel. The value of $440 \mathrm{~J} / \mathrm{ms}$ was obtained, which is the highest value in the combustion of the investigated fuels. The combustion of other fuels resulted in an increased delay of the autoignition, thus delayed heat release. The maximum values of $\mathrm{dQ} / \mathrm{dt}$ were approximately $400 \mathrm{~J} / \mathrm{ms}$ and occurred approximately $6.8 \mathrm{~ms}$ later.

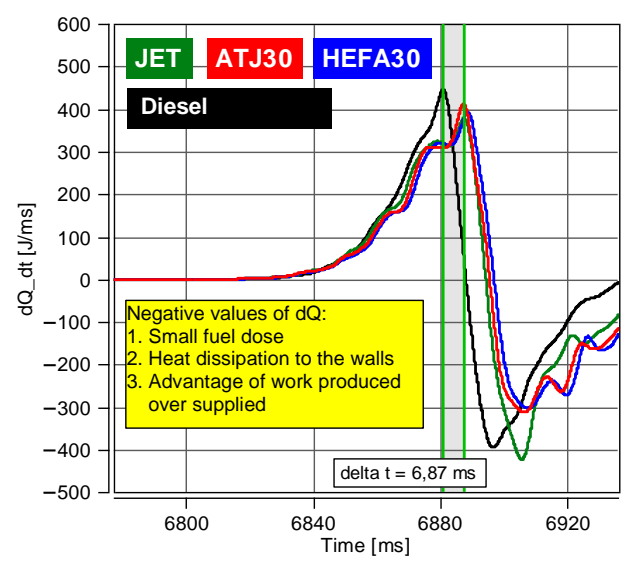

Figure 12. Analysis of the course of heat release during the combustion of the investigated fuels.

\subsection{Assessment of the Combustion Process Based on the Optical Research}

The previously mentioned optical research possibilities in combustion engines and $\mathrm{RCM} / \mathrm{RCEM}$ were used to explore the autoignition spots of the analyzed fuels.

The analysis aimed at:

1. determining the intensity of the autoignition spots,

2. determining the intensity of the changes of this area

The processing of the images was carried out with DaVis software by LaVision (Figure 13). The diagram of the image processing has been shown in the same figure. On the left, we can see a raw image and on the right—an already processed one. The images were recorded with the resolution of $768 \times 768$ pixels at $5 \mathrm{kHz}$. Based on the image recorded as 'raw', the authors cut the analyzed area and removed the inactive part. As a result, circular images were obtained related only to the in-cylinder process analysis without the need to process the outstanding inactive part of the image. 


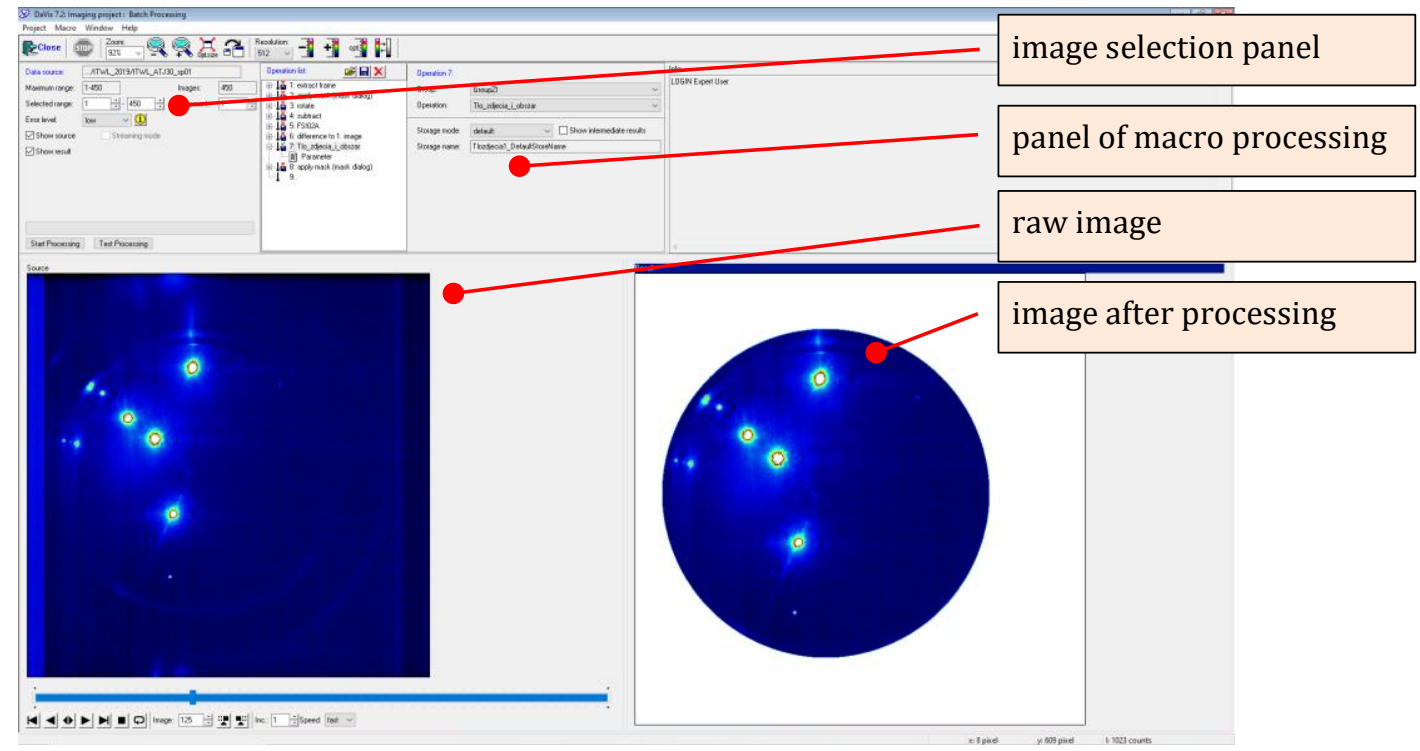

Figure 13. Software for the image analysis.

The sequence of the autoignition spots pertains to the images with the dwell time of $\mathrm{dt}=2.5 \mathrm{~ms}$ (every 10th image). The analysis was initiated from the 65th image (the first autoignition spot appeared there). This denotes the time of $65 \times 0.2 \mathrm{~ms}=13 \mathrm{~ms}$ from the start of the falling curve of the camera-controlling signal. The point in time, from which the autoignition spots were analyzed, was marked with a second vertical green line in Figure 14. The first line denotes the time when the camera was initiated.

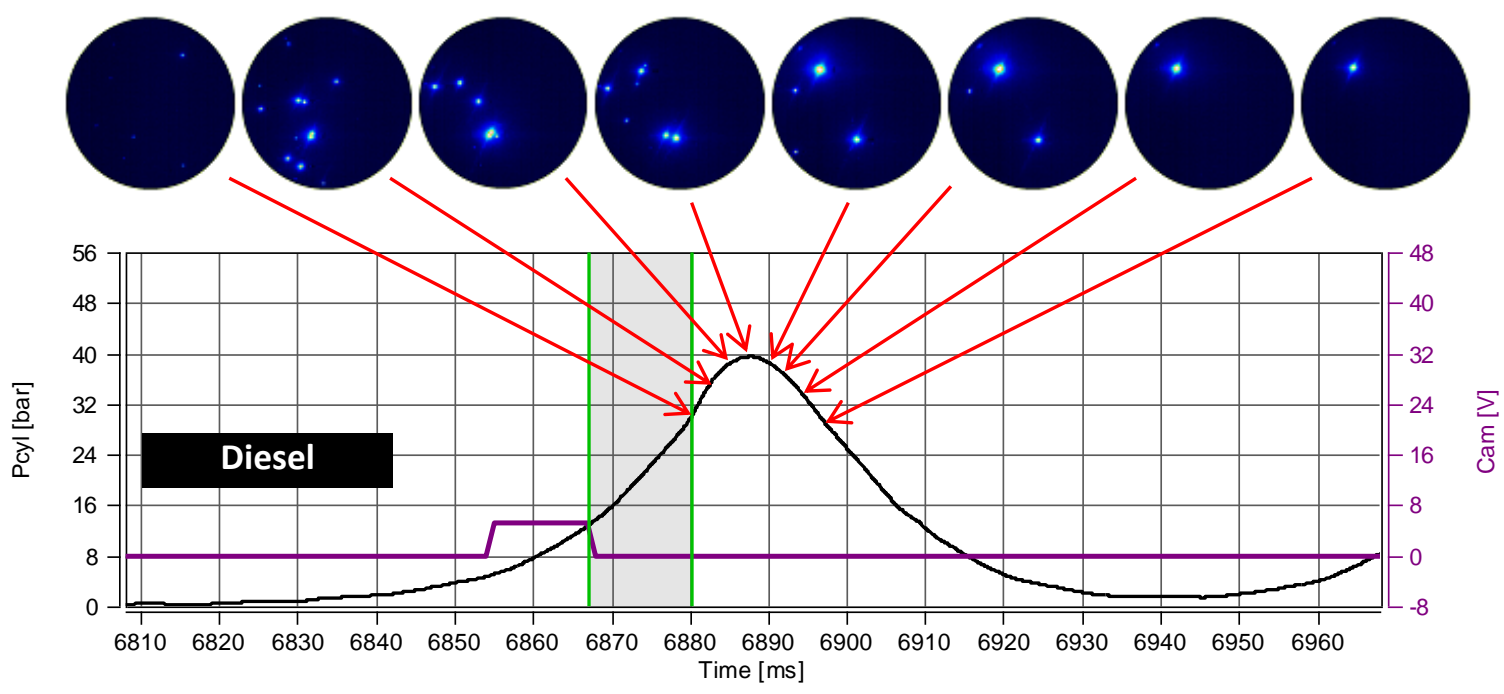

Figure 14. Location of the autoignition spots when combusting diesel oil (indicator graph) (dt for the images: $2.5 \mathrm{~ms}$ ).

The analysis of the combustion of the JET fuel started from the 90th image (the first autoignition spot appeared there). This denotes the time $90 \times 0.2 \mathrm{~ms}=18 \mathrm{~ms}$ from the start of the falling curve of the camera-controlling signal (Figure 15). As before, the point in time, from which the autoignition spots were analyzed, was marked with a second vertical green line. One can see an increased intensity of the autoignition spots compared to the diesel fuel. The spots were larger and of identical glow intensity. 


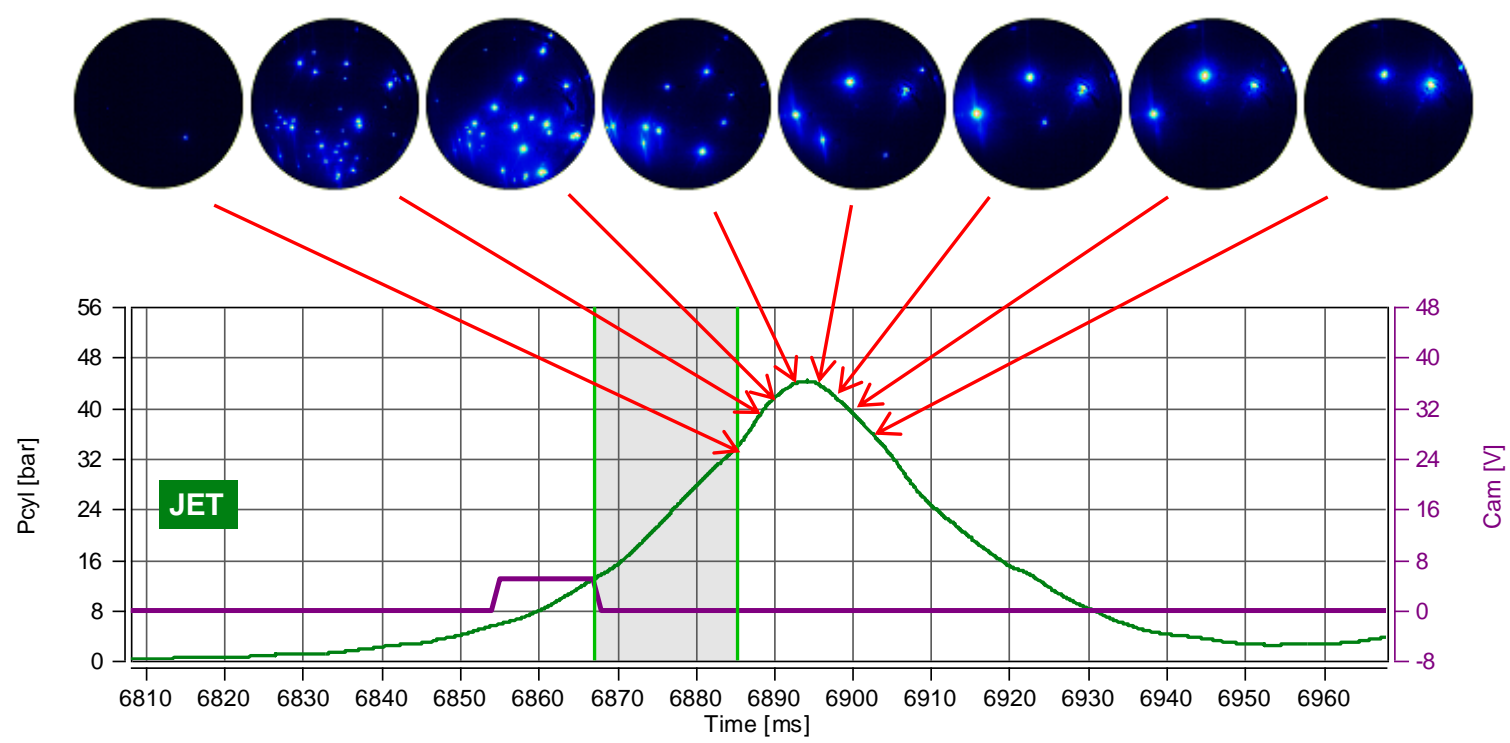

Figure 15. Location of the autoignition spots on the indicator graph during the combustion of the JET fuel (dt for the images: $2.5 \mathrm{~ms}$ ).

The analysis of the combustion of the ATJ30 fuel started from the 93rd image (the first autoignition spot appeared there). This denotes the time $93 \times 0.2 \mathrm{~ms}=18.6 \mathrm{~ms}$ from the start of the falling curve of the camera-controlling signal. The point in time, from which the autoignition spots were analyzed, was marked with a second vertical green line in Figure 16. One can see an increased intensity of the autoignition spots compared to the diesel fuel and, at the same time, its decreased intensity compared to the JET fuel. The spots were slightly smaller and the glowing intensity was lower compared to the JET fuel. Nevertheless, slightly higher values of the maximum combustion pressure were obtained.

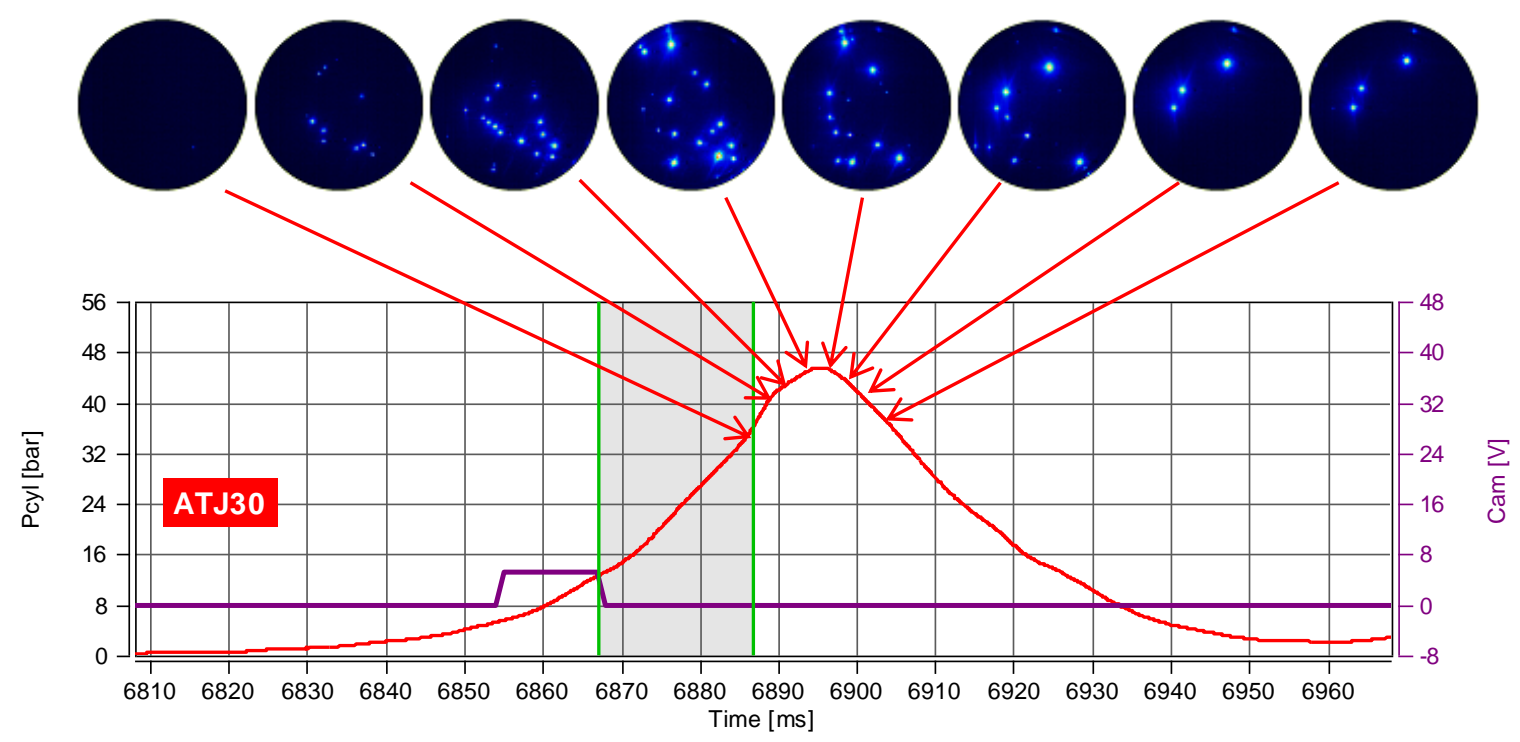

Figure 16. Location of the autoignition spots on the indicator graph during the combustion of the ATJ30 fuel ( $\mathrm{dt}$ for the images: $2.5 \mathrm{~ms}$ ).

The analysis of the combustion of the HEFA30 fuel started from the 95th image (the first autoignition spot appeared there). This denotes the time $95 \times 0.2 \mathrm{~ms}=19.0 \mathrm{~ms}$ from the start of the falling curve of the camera-controlling signal. As before, the point in time from which the autoignition spots were analyzed was marked with a second vertical green line (Figure 17). One can see an increased intensity of the autoignition spots compared 
to the previously tested fuels. The spots were slightly smaller and the glowing intensity high, similarly to the ATJ30 fuel. The greatest values of the maximum combustion pressure were obtained.

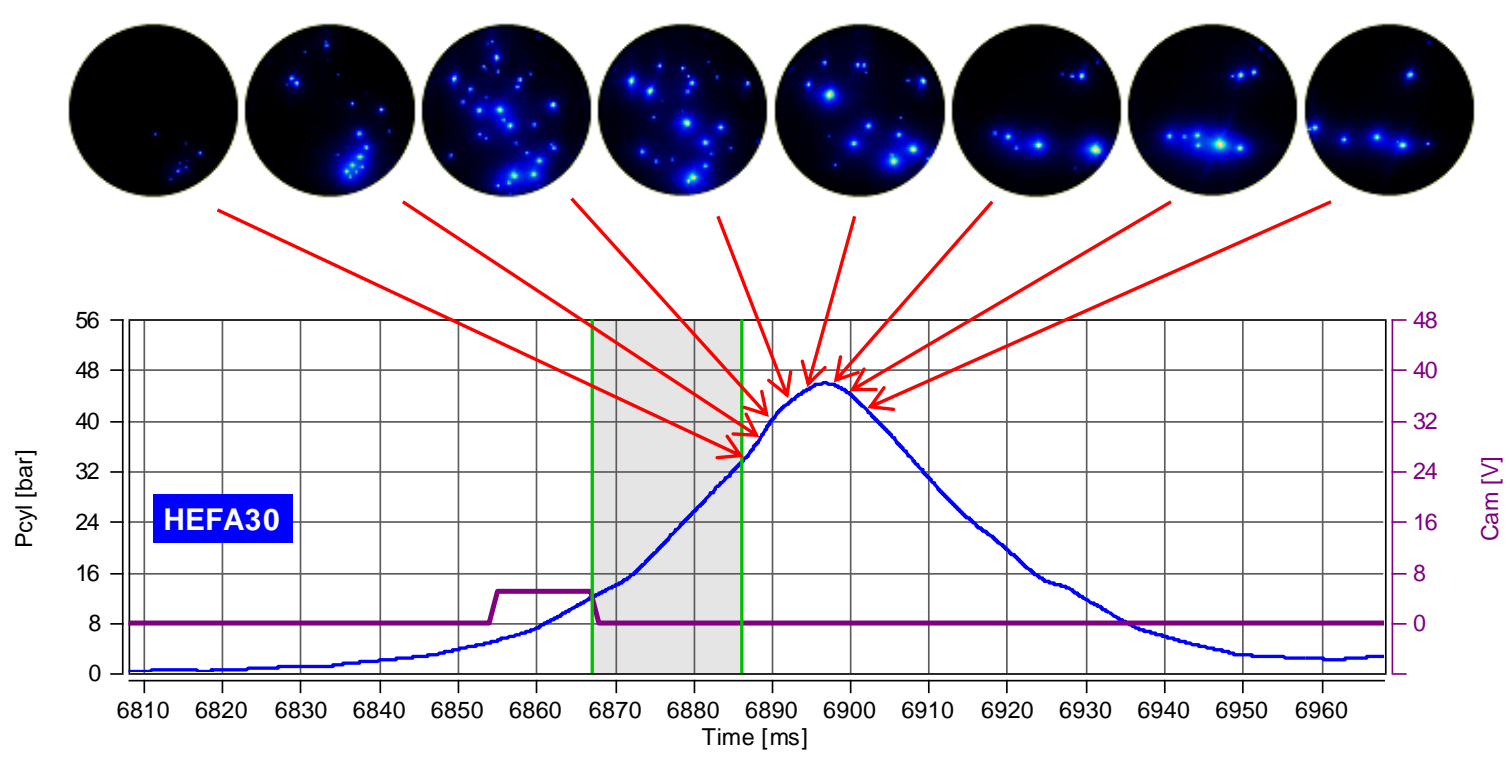

Figure 17. Location of the autoignition spots on the indicator graph during the combustion of the HEFA30 fuel ( $\mathrm{dt}$ for the images: $2.5 \mathrm{~ms}$ ).

Based on the optical research, the lowest autoignition delay was obtained during the combustion of the diesel fuel. This was also confirmed in the indicator research. The autoignition spots were scattered and not particularly intense. This resulted in low combustion pressures.

The combustion of the outstanding fuels resulted in much higher values of the autoignition delay. Despite the greater delay in the autoignition, the optical analysis of the early flame processes indicates that during the combustion of the jet fuel one could observe a large number of autoignition spots in their initial phase with high glowing intensity. This indicates a high autoignition propagation rate.

The combustion of the ATJ30 fuel also indicated a significant autoignition delay at a high rate of formation of the autoignition spots. However, one could observe their slower formation compared to the JET fuel. The analysis of the images indicates an approximate $2.5 \mathrm{~ms}$ delay. This results from the fact of presenting of every 10th image.

In the case of the HEFA30 fuel, the number of autoignition spots was high and so was their rate of expansion. We could also observe their high glowing intensity, which suggests rapid flame formation.

\section{Conclusions}

The assessment of the autoignition of modified jet fuels indicates a varied course of the pre-flame processes. Their versatility suggests different combustion processes of these fuels. All the analyzed fuels showed increased autoignition delay compared to the reference fuel (diesel fuel). The best properties in terms of the pre-flame processes and combustion had the HEFA30 fuel.

The analysis of the indicator and optical research suggests the following properties of the investigated fuels:

1. The most stable fuel in terms of repeatability of the course of its combustion pressure and the time of occurrence of the maximum thereof was the HEFA30 fuel.

2. In the case of the HEFA30 fuels, there were a high number of autoignition spots and their intensity was also significant. Their brightness was the highest, which suggests a possibility of a quick flame formation. 
3. The combustion of all JET-based fuels resulted in a similar course thereof; for these fuels, similar values of the maximum pressures were obtained with only slightly different angles of their occurrence.

4. The highest value of dPcyl/dt was obtained for the combustion of the HEFA30 fuel, yet, the earliest pressure increment was observed for the JET fuel.

5. The autoignition delay in the case of the HEFA30 and the JET fuels was similar. It was shorter by approximately $2 \%$ compared to the AJT30 fuel. The shortest delay was recorded for the diesel fuel.

6. The combustion of the ATJ30 fuel indicates a high value of the autoignition delay and a high intensification of the spot formation, yet the formation was slower compared to the JET fuel. The analysis of the images indicates an approximate $2.5 \mathrm{~ms}$ delay (every 10th image was shown).

7. Similarly to the course of the in-cylinder pressure, an earlier heat release was observed for the diesel fuel. The highest obtained value during the combustion of all the investigated fuels was $440 \mathrm{~J} / \mathrm{ms}$ for this fuel. The combustion of the outstanding fuels resulted in an increase of the autoignition delay and a retardation of the heat release. The maximum values of $\mathrm{dQ} / \mathrm{dt}$ were approximately $400 \mathrm{~J} / \mathrm{ms}$ and occurred approximately $6.8 \mathrm{~ms}$ later.

8. During the combustion of the diesel fuel, the smallest autoignition delay was observed. This is also confirmed by the indicator research. The autoignition spots were very scattered and of moderate intensity, which resulted in small values of the combustion pressure.

9. The combustion of the outstanding fuels resulted in much greater values of the autoignition delay. The combustion of the JET fuel resulted in a high glowing intensity and a high number of autoignition spots in the initial phase. This indicates a high rate of ignition propagation.

The analyzed fuels indicate a huge research potential and the possibility of their application in the analyzed engines. Further works in this matter should focus on the emission-related analyses of these fuels under varied engine loads.

Author Contributions: Conceptualization, J.M., I.P., and A.Ł.; Methodology, J.M. and A.Ł.; Software, I.P.; Validation, J.M., I.P., and A.Ł.; Formal analysis, J.M. and I.P.; Investigation, I.P. and A.Ł.; Resources, A.Ł.; Data curation, J.M., I.P., and A.Ł.; Writing-original draft preparation, J.M., I.P., and A.Ł.; Writing—review and editing, I.P. and A.Ł.; Visualization, I.P. and A.Ł.; Supervision, J.M.; Project administration, I.P. and A.Ł.; Funding acquisition, A.Ł. All authors have read and agreed to the published version of the manuscript.

Funding: This research received no external funding.

Institutional Review Board Statement: Not applicable.

Informed Consent Statement: Not applicable.

Data Availability Statement: The data presented in this study are available on request from the corresponding author.

Conflicts of Interest: The authors declare no conflict of interest.

\section{References}

1. Assessment and Standards Division Office of Transportation and Air Quality U.S. Environmental Protection Agency and AEE300-Emissions Division Office of Environment and Energy Federal Aviation Administration. Recommended Best Practice for Quantifying Speciated Organic Gas Emissions from Aircraft Equipped with Turbofan, Turbojet, and Turboprop Engines, EPA-420-R-09-901. 2009. Available online: www.epa.gov/regulations-emissions-vehicles-and-engines/organic-gas-speciationprofile-aircraft (accessed on 2 December 2020).

2. Control of Air Pollution from Airplanes and Airplane Engines: GHG Emission Standards and Test Procedures, Environmental Protection Agency. 40 CFR Part 1030. 2021. Available online: www.epa.gov (accessed on 2 December 2020).

3. Annex 16 to the Convention on International Civil Aviation-Environmental Protection, Volume II-Aircraft Engine Emissions, International Civil Aviation Organization. 2017. Available online: www.icao.int (accessed on 3 December 2020). 
4. Kim, B.Y.; Fleming, G.G.; Lee, J.J.; Waitz, I.A.; Clarke, J.P.; Balasubramanian, S.; Malwitz, A.; Klima, K.; Locke, M.; Holsclaw, C.A.; et al. System for assessing Aviation's Global Emissions (SAGE), part 1: Model description and inventory results. Transp. Res. Part D Transp. Environ. 2007, 12, 325-346. [CrossRef]

5. Philbin, A. Continuing traffic growth and record airline profits highlight 2015. In Air Transport Results; ICAO Report: Montreal, QC, Canada, 2015.

6. Guzman, J.; Brezinsky, K. Experimental and modeling study of the oxidation of F-24 jet fuel, and its mixture with an iso-paraffinic synthetic jet fuel, ATJ. Combust. Flame 2020. [CrossRef]

7. Flora, G.; Balagurunathan, J.; Saxena, S.; Cain, J.P.; Kahandawala, M.S.; DeWitt, M.J.; Sidhu, S.S.; Corporan, E. Chemical ignition delay of candidate drop-in replacement jet fuels under fuel-lean conditions: A shock tube study. Fuel 2017, 209, 457-472. [CrossRef]

8. Xue, X.; Hui, X.; Singh, P.; Sung, C.J. Soot formation in non-premixed counterflow flames of conventional and alternative jet fuels. Fuel 2017, 210, 343-351. [CrossRef]

9. Wang, H.; Oehlschlaeger, M.A. Autoignition studies of conventional and Fischer-Tropsch jet fuels. Fuel 2012, 98, 249-258. [CrossRef]

10. Mayhew, E.K.; Mitsingas, C.M.; Coburn, V.D.; Temme, J.E.; Kweon, C.B.M. Effects of fuel blending on first stage and overall ignition processes. Proc. Combust. Inst. 2020. [CrossRef]

11. Wei, H.; Liu, W.; Chen, X.; Yang, Q.; Li, J.; Chen, H. Renewable bio-jet fuel production for aviation: A review. Fuel 2019, $254,115599$. [CrossRef]

12. Stöhr, M.; Ruoff, S.; Rauch, B.; Meier, W.; Le Clercq, P. Droplet vaporization for conventional and alternative jet fuels at realistic temperature conditions: Systematic measurements and numerical modeling. Proc. Combust. Inst. 2020. [CrossRef]

13. Kumar, K.; Sung, C.-J.; Hui, X. Laminar flame speeds and extinction limits of conventional and alternative jet fuels. Fuel 2011, 90, 1004-1011. [CrossRef]

14. de Oliveira, P.M.; Mastorakos, E. Mechanisms of flame propagation in jet fuel sprays as revealed by OH/fuel planar laser-induced fluorescence and $\mathrm{OH}^{*}$ chemiluminescence. Combust. Flame 2019, 206, 308-321. [CrossRef]

15. Schripp, T.; Herrmann, F.; Oßwald, P.; Köhler, M.; Zschocke, A.; Weigelt, D.; Mroch, M.; Werner-Spatz, C. Particle emissions of two unblended alternative jet fuels in a full scale jet engine. Fuel 2019, 256, 115903. [CrossRef]

16. Lobo, P.; Condevaux, J.; Yu, Z.; Kuhlmann, J.; Hagen, D.E.; Miake-Lye, R.C.; Whitefield, P.D.; Raper, D.W. Demonstration of a regulatory method for aircraft engine nonvolatile PM emissions measurements with conventional and isoparaffinic kerosene fuels. Energy Fuels 2016, 30, 7770-7777. [CrossRef]

17. Engineering ToolBox. Fuels and Chemicals-Autoignition Temperatures. 2003. Available online: https://www.engineeringtoolbox. com/fuels-ignition-temperatures-d_171.html (accessed on 3 December 2020).

18. Kapusta, L.J.; Pielecha, I.; Wisłocki, K.; Teodorczyk, A. Autoignition and combustion of n-hexane spray in subcritical and supercritical environments. J. Therm. Anal. Calorim. 2016, 123, 819-828. [CrossRef]

19. Pielecha, I.; Cieślik, W.; Szałek, A. Operation of hybrid propulsion systems in conditions of increased supply voltage. Int. J. Precis. Eng. Manuf. 2017, 18, 1633-1639. [CrossRef]

20. Waligórski, M.; Batura, K.; Kucal, K.; Merkisz, J. Research on airplanes engines dynamic processes with modern acoustic methods for fast and accurate diagnostics and safety improvement. Measurement 2020, 154, 107460. [CrossRef]

21. Merkisz, J.; Tomaszewski, F.; Szymański, G.; Waligórski, M. Application of the time-frequency selection of the vibration signal for misfire sensing in diesel engines. In SAE Technical; SAE International: Warrendale, PA, USA, 2009. [CrossRef]

22. Fiedkiewicz, Ł.; Pielecha, I. Relations between ion signal and flame propagation in cylinder of a rapid compression machine. Combust. Engines 2019, 179, 264-268. [CrossRef]

23. Merkisz, J.; Pielecha, J.; Pielecha, I. Road test emissions using on-board measuring method for light duty diesel vehicles. Jordan J. Mech. Ind. Eng. 2011, 5, 89-96.

24. Hamzehloo, A.; Aleiferis, P. Numerical modelling of mixture formation and combustion in DISI hydrogen engines with various injection strategies. In SAE Technical; SAE International: Warrendale, PA, USA, 2014. [CrossRef]

25. Rashedul, H.K.; Kalam, M.A.; Masjuki, H.H.; Ashraful, A.M.; Imtenan, S.; Sajjad, H.; Wee, L.K. Numerical study on convective heat transfer of a spark ignition engine fueled with bioethanol. Int. Commun. Heat Mass Transf. 2014, 58, 33-39. [CrossRef]

26. Liu, H.; Zhang, H.; Shi, Z.; Lu, H.; Zhao, G.; Yao, B. Performance characterization and auto-ignition performance of a rapid compression machine. Energies 2014, 7, 6083-6104. [CrossRef]

27. Monteiro, E.; Julien, S.; Bellenoue, M.; Moreira, N.A.; Malheiro, S. Experimental study of syngas combustion at engine-like conditions in a rapid compression machine. Exp. Therm. Fluid Sci. 2011, 35. [CrossRef]

28. Park, P.; Keck, J.C. Rapid compression machine measurements of ignition delays for primary reference fuels. In $S A E$ Technical; SAE International: Warrendale, PA, USA, 1990; p. 900027.

29. Pielecha, I.; Borowski, P.; Cieślik, W. Investigations into high-pressure diesel spray-wall interaction on reduction of exhaust emission from DI diesel engine. In SAE Technical; SAE International: Warrendale, PA, USA, 2014. [CrossRef]

30. Curto-Risso, P.L.; Medina, A.; Calvo Hernandez, A.; Guzman-Vargas, L.; Angulo-Brown, F. On cycle-to-cycle heat release variations in a simulated spark ignition heat engine. Appl. Energy 2011, 88, 1557-1567. [CrossRef]

31. Das, A.K.; Sung, C.-J.; Zhang, Y.; Mittal, G. Ignition delay study of moist hydrogen/oxidizer mixtures using a rapid compression machine. Int. J. Hydrogen Energy 2012, 37, 6901-6911. [CrossRef] 
32. Mittal, G.; Sung, C.-J. A rapid compression machine for chemical kinetics studies at elevated pressures and temperatures. Combust. Sci. Technol. 2007, 179, 497-530. [CrossRef]

33. Jwa, K.; Nam, V.D.; Setiawan, A.; Lim, O. Experimental study of the ignition delay of gasoline/biodiesel blends using a rapid compression expansion machine. Energy Procedia 2019, 158, 655-660. [CrossRef]

34. EL-Seesy, A.I.; Kayatas, Z.; Takayama, R.; He, Z.; Kandasamy, S.; Kosaka, H. Combustion and emission characteristics of RCEM and common rail diesel engine working with diesel fuel and ethanol/hydrous ethanol injected in the intake and exhaust port: Assessment and comparison. Energy Convers. Manag. 2020, 205, 112453. [CrossRef] 